Review

\title{
Near Infrared (NIR) Light Therapy of Eye Diseases: A Review
}

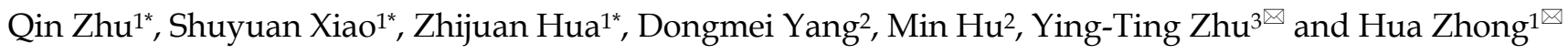 \\ 1. Department of Ophthalmology, the First Affiliated Hospital of Kunming Medical University, Kunming 650031, China \\ 2. Department of Ophthalmology, the Second People's Hospital of Yunnan Province, Kunming 650021, China \\ 3. Tissue Tech Inc, Miami, Florida 33126, USA \\ *The first three authors contribute equally to this manuscript. \\ $\triangle$ Corresponding authors: Hua Zhong, M.D., Ph.D. Department of Ophthalmology, the First Affiliated Hospital of Kunming Medical University, 295 Xichang \\ Rd, Kunming 650031, China; Telephone: 86-138-8818-8920; Fax: 86-0871-6533-6015; E-mail: zhoculist@163.com or Ying-Ting Zhu, D.V.M, Ph.D. Research and \\ Development Department, TissueTech, Inc., 7300 Corporate Center Drive, Suite B, Miami, FL 33126, USA. Telephone: (786) 456-7632; Fax: (305) 274-1297; E-mail: \\ yzhu@tissuetechinc.com
}

(c) The author(s). This is an open access article distributed under the terms of the Creative Commons Attribution License (https://creativecommons.org/licenses/by/4.0/). See http://ivyspring.com/terms for full terms and conditions.

Received: 2020.09.07; Accepted: 2020.10.15; Published: 2021.01.01

\begin{abstract}
Near infrared (NIR) light therapy, or photobiomodulation therapy (PBMT), has gained persistent worldwide attention in recent years as a new novel scientific approach for therapeutic applications in ophthalmology. This ongoing therapeutic adoption of NIR therapy is largely propelled by significant advances in the fields of photobiology and bioenergetics, such as the discovery of photoneuromodulation by cytochrome c oxidase and the elucidation of therapeutic biochemical processes. Upon transcranial delivery, NIR light has been shown to significantly increase cytochrome oxidase and superoxide dismutase activities which suggests its role in inducing metabolic and antioxidant beneficial effects. Furthermore, NIR light may also boost cerebral blood flow and cognitive functions in humans without adverse effects. In this review, we highlight the value of NIR therapy as a novel paradigm for treatment of visual and neurological conditions, and provide scientific evidence to support the use of NIR therapy with emphasis on molecular and cellular mechanisms in eye diseases.
\end{abstract}

Key words: near infrared light, photobiomodulation therapy, mechanism, eye disease

\section{Introduction}

Light is a form electromagnetic radiation characterized by particle- and wave-like properties. Electromagnetic radiation waves have unidirectional vectors, characterized by wavelengths $(\lambda$, distance in successive peaks), frequencies (oscillations per second), and amplitudes (difference of trough and peak). The energy particles within electromagnetic radiation includes photons, which travel at $3 \times 10^{8} \mathrm{~m}$ per second. Therefore, a mixture of waves will have photons traveling at various amplitudes and frequencies that are scattered and absorbed, which can be reflected by numerous objects, such as biological materials. As more and more studies have been performed to determine on how to harness this energy, the applications of light to medical therapy has advanced dramatically worldwide, for example, laser therapy is now a common treatment in certain specialties and has been shown effective for many chronic diseases without side effects.

More recently, low-level light therapy in the far-red (FR) to near-infrared (NIR) range of the spectrum ( $\sim 600-1000 \mathrm{~nm})$, collectively termed photobiomodulation (PBM), has gained worldwide attention in recent years as a novel tool for experimental therapeutic applications in a variety of medical conditions. For instance, applications of PBM to medical disorders, has been shown to restore functions of damaged mitochondria by upregulating cytoprotective factors and protecting against damage [1]. These findings suggest laser therapy may inhibit inflammation and promote immune response and wound healing for various tissues (reviewed in [2]).

This review will concisely describe the history of the modality, the current proposed mechanisms of 
action of NIR light at the molecular, cellular, and nervous tissue levels, the clinical indications and applications of photobiomodulation therapy (PBMT), the results of clinical studies, and the potential other benefits of PBMT in eye diseases.

\section{NIR Light, LEDs, PBMT and Lasers}

The light brightness and color are determined by the number of photons and energy of each photon. NIR light therapy uses directional low-power but high-fluency light, monochromatic or quasimonochromatic, from lasers or light-emitting diodes (LEDs) in the wavelengths, red to near-infrared, to mediate biological functions or to promote therapeutic effects in a safe way $[3,4]$ (also reviewed in [5]).

A laser is defined as a device to emit light by optical amplification, theoretically contingent on the stimulation of electromagnetic radiation emission. The word "laser" originated from the acronym of Light Amplification through Stimulation of Emission Radiation. The first laser was invented by Theodore H. Maiman in Hughes Research Laboratories in 1960. After its development, the laser has been increasingly used as a medical therapy, including low light therapy, low laser therapy and phototherapy or PBMT.

PBMT is a kind of light therapy using non-ionizing light sources, such as broadband light, lasers, and LEDs in visible or infrared spectrum. PBMT uses low-power but effective monochromatic light from LEDs in the wavelengths from red to near-infrared region to mediate biological events or therapeutic effects without any side effects [3, 4]. This has been shown to protect against retinal degeneration by reducing light-induced stress, inflammation and cell death [6], to promote contrast sensitivity and visual acuity in macular degeneration [7], to elevate phagocytosis, to reduce reactive oxygen species production [8], and to decrease structural and functional damages in Diabetic Retinopathy [9].

NIR and LEDs light can activate photoreceptor cytochrome $c$ oxidase, leading to elevated energy metabolism, increased wound healing, and inhibited toxicity (reviewed in [10]). The applications of NIR light is to convert luminous energy into metabolic energy to modify biological functions of cells. Compared to the effects of high-energy photon by lasers, which result in heating and destruction to living tissues and cells, NIR light is in the low level since the energy level of electromagnetic radiation is negatively associated to its wavelength. In addition, the tissue is usually targeted by low irradiances, which does not cause side effects because energy delivered from NIR light is low enough not to cause heating and tissue destruction but high enough to mediate cell and tissue functions. For example, photodynamic therapy has been used for skin condition applications without side effects [11], and electrical photoneuromodulation in neurons may be obtained without thermal effects [12]. Clinically, the therapeutic optical window corresponding to the red to near-infrared wavelengths, matches the luminous energy which promotes excitation of susceptible intracellular molecules in vivo [13]. That is why NIR light is termed near-infrared light therapy, based on the theory that some molecules in living cells and tissues may absorb photons, initiating signaling pathways triggered by light [14]. This results in energy conversion in which certain molecules may be excited by light, reaching an electronically excited state, which changes their conformation and function and activates signaling pathways to mediate cellular metabolism. In contrast to conventional laser high energy, destructive effects such as enormous heating, tissue destruction by ablation, coagulation, dissection and vaporization does not occur.

\section{NIR Light Resources}

On earth, the primary source of electromagnetic radiation is solar energy from sunlight. Solar energy contains multiple waves in the electromagnetic spectrum, for example, wavelengths in the visible spectrum is multidirectional and not synchronized in time and space. In contrast, NIR light is monochromatic, which allows high specificity in molecular biomodulation. NIR light may be obtained by LEDs arrays and lasers, which are applied to PBM of eyes. Lasers can produce efficient coherent light energy to permit high penetration of tissues and such constant beam delivers energy to circumscribed areas. The beam width from lasers may be enhanced by their coupling into fiber optic to allow distribution of energy to larger areas. LEDs can produce efficient but not coherent light in wavelengths between 4-10 nm. Nevertheless, LEDs only produce negligible heat, impossible for thermal injury [15]. In addition, LEDs can be coupled to arrays with ergonomic functions, to allow delivery of efficient energy to a large area, for example, the brain. In fact, LEDs have been evaluated in human trials and have been approved by the FDA [16].

\section{NIR Photoreceptors and Targets}

As NIR light can cause various changes in physiological and pathological conditions, it has long been suspected that the light must act on certain receptors in living cells and tissues. For example, opsins in animals absorbs light, which induces phototransduction within photoreceptors. Photoreceptors include specialized and nonspecialized photoreceptors in mammalian cells. Hemoglobin, 
melanin, oxyhemoglobin and water absorb light from broad ranges of wavelengths. In the wavelength range of $600-1000 \mathrm{~nm}$, the absorption curve is minimal, supplying a window for light to activate certain photoreceptors. In fact, the cells are sensitive to light from far-red (FR) to NIR, which can promote photon therapy by change of cell metabolism, proliferation and migration. For instance, after 3 days under 628 $\mathrm{nm}$ light, mitochondrial respiratory and antioxidant genes are upregulated and apoptotic and stress-related genes are downregulated in human fibroblasts due to activation of cytochrome c oxidase [17]. The question is what molecule(s) in cells was activated for the effective treatment by NIR light. It is inferred that the wavelengths in red and near-infrared range are responsible for effective photobiological therapy. Another example is photoreceptors in hemoglobin of mammalian tissues, showing differential light absorption according to redox state, which allows its quantification and oxygenation in clinical applications. Except hemoglobin, other photoreceptors in red and near-infrared range are heme-containing metalloproteins, for example, cytochrome c oxidase and myoglobin. Cytochrome c oxidase, which can be activated by light from FR to NIR range, cause cellular changes $[16,18]$. In addition, other molecules such as catalase, cryptochromes superoxide dismutase, cytochrome $c$, cytochrome b, guanylate cyclase and nitric oxide synthase also have photoreceptors [15].

Although many photoreceptors have been discovered, the mechanism of NIR light is still unclear because many molecules have photoreceptor capabilities. In addition, reaction by a molecular target to a specific effective wavelength may be multiple. For instance, flavoprotein and $\mathrm{NADH}$-dehydrogenase have photoreceptors not only in the violet-to-blue but also in red and near-infrared spectral regions [18]. In addition, both terminal oxidases and superoxide dismutase have absorption peaks at high wavelengths of $670-680 \mathrm{~nm}$, overlapping in the absorption spectrum of different photoreceptors $[18,19]$. This implies that the effect of other photoreceptors to one biological effect cannot be excluded. Interestingly, research on the nervous system is the first to identify an important photoreceptor mediating biological effects by NIR light. Isolated mitochondria are responsive to irradiation by monochromatic light in red to near-infrared spectrum. Light could promote mitochondrial membrane potential, promote ATP exchange, RNA and protein synthesis by mitochondria, and increase usage of oxygen [20]. The effects from NIR light on mitochondria are wavelength-specific, and molecules absorbing NIR light in living cells are likely respiratory components [21]. Further research on mitochondrial photoreceptors has been performed by action spectra analysis-descriptions of biological responses to NIR light as function from a wavelength. For example, RNA synthesis in HeLa cells could be promoted by certain wavelengths, but not by other wavelengths. General speaking, the wavelength inducing maximal effect can be found in a range of effective wavelengths, which is helpful to identify photoreceptor-mediated signaling by NIR light. In fact, the bands in the action spectrum is in the absorption spectrum of mitochondrial cytochrome oxidase [18]. Cytochrome oxidase is identified as a primary photoreceptor of light in red and near-infrared region in electromagnetic spectrum [22, 23], which is a key oxidase in cell bioenergetics in nerve cells from retina and brain [24]. Cytochrome oxidase is the key enzyme in electron transfer 360 in mitochondria, catalyzing electron transfer to oxygen from cytochrome c, reducing $\sim 95 \%$ of oxygen taken by eukaryotic cells. Cytochrome oxidase also acts as a redox-coupled proton pump to promote formation of transmembrane electrochemical gradient, and as a rate-limiting step to synthesize energy-storing ATP [25]. Cytochrome oxidase is involved in neuronal and free radical metabolism, apoptosis process and glutamatergic regulation [26, 27]. Cytochrome oxidase activity is strongly associated with neuronal function and is a specific marker for intraneuronal metabolic activity [27]. In addition, cytochrome oxidase may only be the primary photoreceptor in its intermediate but not final forms by analysis of sequential irradiation $[28,29]$. Absorption spectra in cytochrome oxidase with different oxidative states are parallel to action spectra in biological responses of NIR light [28].

\section{NIR Light Effects and Applications}

NIR light dosimetry is hormetic dose-response with a curve in a bell-shape or U-shape or biphasic shape, characterized by promotion of biological process at a low dose but inhibition of biological process at a high dose. Hormetic curves are better than linear curves in accurately predicting biological responses under pharmacological threshold [30]. It is very important since stimulatory responses from NIR light are mild, $\sim 30 \%$ to $60 \%$ above controls. In contrast, traditional dose-responses are usually increase by several folds. The hormatic dose-response is well known in various NIR light applications, because photo--stimulatory or photo-inhibitory effects are shown in low $\left(0.001 \mathrm{~J} / \mathrm{cm}^{2}\right)$ or high $(.10$ $\mathrm{J} / \mathrm{cm}^{2}$ ) energy densities respectively [31]. Positive responses can be achieved in the dose range for desired therapeutic outcomes [16, 32, 33]. 
Examples of NIR light effects and applications are listed for our understanding of usefulness of NIR light for potential medical applications. For instance, wound healing could appear in rat skin under a ruby laser with low energy [34] or under Gallium laser producing 685- or 830-nm light [35]. Spinal cord injury could be improved under $810-\mathrm{nm}$ light in rat [36]. NIR light was beneficial for treating gingival incisions [37], oral mucositis [38], ulcers of skin [39], and wound healing [40], nerve repair [41-43], in carpal tunnel syndrome [44, 45] and soft tissue injuries [46]. Inflammation could appear in light-stressed retina [47-49]. Anti-inflammation by microglial inhibitor naloxone could decrease photoreceptor degeneration in retina [50, 51]. LED pretreatment may protect neurons from cyanide-induced apoptosis by inhibiting reactive oxygen synthesis and apoptosis and promoting energy metabolism [52]. Recently, 670 $\mathrm{nm}$ red light has been found has potential for potential wild medical applications evidently by many research articles. For example, $670 \mathrm{~nm}$ light could protect neuronal cells under treatment of cyanide [16], protect photoreceptors in rat and promote wound healing in primate retina [53], increase mitochondrial metabolism, decrease retinal inflammation, and reduce oxidative cell stress, probably by respiratory chain complex I, II and IV to target cytochrome c oxidase, causing improved energy metabolism in mitochondria [54]. $670 \mathrm{~nm}$ red light is a powerful neuroprotectant against light induced damage [6] and toxins [55]. Treatment with $670 \mathrm{~nm}$ red light decreases retinal inflammation by increasing mitochondria membrane potential [56], improves retinal healing [15], such as reducing raised intracellular pressure in rat retina [57], retards aging retinal functions [58]. $670 \mathrm{~nm}$ LED can mediate inflammation and innate immunity in neural retina in a mouse model of macular degeneration [59], probably by upregulating expression of cytochrome c oxidase, along with reduced inflammation [60]. The respiration of aged retinal mitochondria can be improved by $670 \mathrm{~nm}$ light as demonstrated by increased mitochondrial performance and reduced inflammation via improved oxidation by activated cytochrome c oxidase. Aged retina can have a progressive increase of oxidation by $670 \mathrm{~nm}$ light within only 5 minutes [61]. $670 \mathrm{~nm}$ light may also alter oxygen-mediated degeneration in retina in a mouse model, showing that $670 \mathrm{~nm}$ light decreases expression of oxidative stress markers and reduces in hyperoxia conditions [62]. Pretreatment of $670 \mathrm{~nm}$ light can decrease lipid peroxidation and reduce complement propagation in retina degeneration [63]. Low levels of $670 \mathrm{~nm}$ light may prevent against retinopathy by oxygen induction and lung damage by excessive oxygen [64] and modulate expression of genes involved with inflammation, oxidative metabolism and apoptosis [65]. Although the precise mechanism is unknown, there is strong evidence to suggest that cytochrome $c$ oxidase acts as the primary photo-receptors [66], boosting oxidative metabolism [67] and ATP production [18], and is probably linked to increase of cytochrome c oxidase and reduction of acrolein expression [68], driving reparative and protective mechanisms. In fact, abundant research results supports its potential benefits in retinal disease [33], stroke [69, 70], neurodegeneration [5], neuromuscular disorders [71], hair regrowth [72], memory [73] and mood disorders [74].

\section{Possible Mechanisms in NIR Light Therapy}

Cytochrome oxidase is the primary NIR light photoreceptor, which is especially beneficial to eye and brain because the enzyme is the key enzyme in oxidative metabolism. Eyes and neurons rely on cytochrome oxidase for their metabolism. The effects of NIR light can be primary (during light exposure) and secondary (post light exposure). Primary effects are those of immediate photochemical changes in the photoreceptors activated by light. Therefore, those effects are dependent on light. For example, redox changes of the respiratory chain can be induced by NIR light, which promotes oxidation by cytochrome oxidase, linked to the bell-shaped and dose-dependent cellular responses [4]. NIR light can also promote oxidation of cytochrome $\mathrm{c}$ by cytochrome oxidase, inducing elevated usage of oxygen, increased sensitivity of mitochondrial membrane and pore permeability in mitochondria $[18,19]$. Those effects are caused by increased electron flow in the mitochondrial electron transporting chain. In addition, NIR light can generate free radicals, through singlet oxygen by photodynamic action and superoxide ion by electron auto-oxidation. In addition, NIR light may produce transient heat in chromophore by electric or light oscillations [18]. Such oscillations may affect various molecules in target tissues. NIR light may also strengthen hydrogen promoting energy transfer. Secondary effects from NIR light may appear as results of primary effects, for instance, biochemical and biological reactions which affects cellular homeostasis [4, 75, 76]. NIR light may initiate various signaling pathways from mitochondria to nucleus by sending signals from mitochondria in which photoreceptors are activated, translocated to the nucleus, and in which gene expression is altered. In details, NIR light promotes beneficial changes of NAD/NADH ratio in mitochondria to induce release of nitric oxide by 
activated cytochrome oxidase, and thus to mediate ATP level. ATP can then activate its P2 receptors to cascade inward calcium currents, promoting release of calcium from its intracellular storages [77]. Such changes of ATP can regulate level of cAMP, causing activation of various kinases to alter gene expression, which may regulate inflammation and wound healing.

PBM, or low light therapy, has been recognized for approximately 50 years. However, its cellular and molecular mechanisms are still not very clear. Recently, research on importance of cytochrome c oxidase in PBM has gained interactional attentions. The first hypothesis is that by stimulation of low light, the photons promote dissociation of inhibitory nitric oxide from this enzyme, promoting electron transport and ATP production, potentiating mitochondrial membrane and ATP production, and expression of transcription factors, which promote gene expression, protein synthesis, various cellular and tissue functions (reviewed in [13]). PBM, by photon irradiation from NIR light with low energy, has a history of clinical application for treatment of soft tissue injuries and wound healing for decades. NIR light can penetrate tissues such as the brain, heart and spinal cord [78, 79], accelerate healing from ischemic heart injury [78], inhibit degeneration in injured optic nerve and retina $[3,78]$, and promote recovery in stroke [79-81]. These effects by NIR light are clearly associated with the absorption spectrum of cytochrome oxidase [15]. NIR light initiates changes of redox in cytochrome oxidase, causing activation of intracellular signaling to positively mediate mitochondrial function and intracellular protection by overexpression of cytoprotective factors $[3,16,52,79,82-85]$. NIR light can also promote expression and accumulation of antioxidants and cytoprotective factors [55]. For example, gene profile analysis show that NIR light promote noncoding RNAs (ncRNA) [65]. To understand the role of the noncoding sequence is an interesting topic for further investigation.

PBM can be applied to clinic therapy to ease inflammation and pain, wound healing in bones and tendons via mitochondrial cytochrome $\mathrm{c}$ oxidase to improve electron transport, light ion channels (reviewed in [86]). During PBM, cytochrome oxidase, a primary photoreceptor of NIR light, plays a critical role in a constructive role of recoveries of injured eye and brain tissues because the enzyme in mitochondria is critical for oxidation. For example, NIR light has robust neuroprotective effects in improvement and functional restoration of damaged retina by increase of mitochondrial function, improvement of blood flow to damaged neurons, increase of cell survival factors [87].
PBMT has become increasingly popular in human medicine in recent years. Recent investigations have demonstrated that laser therapy may regulate immune and inflammatory responses and promote wound healing in certain tissues [88]. In addition, energy from PBMT are very limited without any concerns of heating and tissue destruction, but abundant for mediating cell functions. For example, PBMT can be used for photodynamic therapy of skin diseases [11] and for thermal therapy for neuronal diseases [12]. Although cells are sensitive to certain wavelengths in electromagnetic spectrum in vitro, beneficial observations to wavelength are preferentially only a narrower range of wavelength in vivo. For instance, light in visible range (usually 400$700 \mathrm{~nm}$ ) can penetrate and activate retinal cells with specific photopigments in cones and rods. The wavelength from red to near-infrared range is the best to cause beneficial effects in the cells without specific photopigments. This is probably due to the penetrating capacity of wavelengths in certain ranges to penetrate tissue. The lower the wavelengths are, for example, violet and ultraviolet wavelength, the less the wavelength to penetrate, whereas the wavelength in infrared red have higher penetration ability. In addition, energy at wavelengths $<600 \mathrm{~nm}$ is usually widely distributed in living tissues in vivo [13]. For medical purposes, this suggests there is in vivo therapeutic optical ranges from red and near-infrared wavelengths. This optical window also corresponds to the capability of luminous energy to activate intracellular biological molecules [13]. Interestingly, redshifted channel rhodopsin injected into blind rd1 mice may restore light responses of the mice from their retina and cortices to low orange light and ganglion cells from human retina [89]. Therefore, NIR light is also termed near-infrared light therapy. That is, NIR light is hinged on the concept that living biological molecules can absorb photons, activating signaling pathways triggered by light [14]. This biological process is called energy conversion based on the theory that biological molecules activated by light can reach electronically excited state from basal line, which results in changes of conformation and functions, thus inducing activation of certain signaling pathways to mediate cellular metabolism and recovery. Although tremendous progress has been made, details of mechanistic studies are required for further advance of NIR light applications to medical field.

\section{Potential Retinal Therapeutic Applications by NIR Light}

Evidence has suggested that NIR light may restore biological function of damaged mitochondria, 
upregulate cytoprotective factors and inhibit apoptosis. Photons from NIR light can penetrate diseased retina, be absorbed by mitochondrial photoreceptors such as cytochrome $\mathrm{c}$ oxidase to promote mitochondrial energy beneficial metabolism, elevate production of cytoprotective factors and prevent apoptosis.

The examples of NIR light to potential medical applications are listed below. NIR light can protect retina in injury in which mitochondrial energy metabolism is damaged by a retinal injury model manipulated by methanol [53]. NIR light may decrease damage in the layer outside nucleus and protect the wave amplitude of electroretinogram $b$ [90]. Surprisingly, protective effects from NIR light lasts as much as a month from damage, linked to increase of mRNA expression in neuroprotection. NIR may also protect photoreceptors, avoid cell death due to phototoxicity with decreased multiple gene expression induced by light damage [65]. Remarkably, NIR light may reduce death of photoreceptors by 70\% [91]. NIR light can also inhibit cell degeneration of retinal ganglion cells caused by inhibitor rotenone to the mitochondrial complex I [1]. NIR light treatment can also promote drusen, yellow deposits from macular degeneration due to aging, lower intraocular pressure as long as several months [6], indicating that NIR light can have beneficiaries in retinal and optic nerves.

Mitochondrial degeneration and oxidative damage of retina are shown in retinal degeneration and other damages, for example, aging macular degeneration, light-stimulated retinal damage, methanol intoxication and retinitis pigmentosa [92-94]. NIR light may activate mitochondria signaling pathways to promote mitochondrial function, induce expression and activation of cytoprotective factors, inhibit oxidative stress, and protect neurons from death in in vitro neurons and in vivo animal models for neuronal injuries $[5,15,16,18$, 76].

\section{Potential Optic Therapeutic Applications by NIR Light}

Light penetration from NIR light rely on target tissues, wavelengths, and sources of NIR light. NIR light is safe but effective. Within near-infrared wavelengths, light can penetrate eyes at maximal level, but absorption of light by cornea and lens is at minimal level (approximately 10\%) [95]. The neurons from retina require high energy, or mitochondrial ATP to satisfy tissue requirements [96-98]. Like other neurons, retinal neurons are very sensitive to depletion of glucose or lack of energy, oxidative stress and malfunction of mitochondria [99, 100].
Mitochondrial malfunction plays a critical role in retinal neurodegeneration [101]. Optic neuron damages are characterized by high morbidity and mortality, without any effective treatments at present [102-105]. Alzheimer's patients have fewer retinal ganglion cells, ganglion axons, than healthy people $[104,106,107]$. Leber's optic neuropathy, a mitochondrial disease, can lead to $\sim 2 \%$ of all blindness patients in this world [108]. Therefore, cellular degeneration from retinal ganglion cells is a major health problem in this world. Other genetic disorders include Leigh syndrome [109, 110], Friedreich's ataxia [111], myoclonic epilepsy due to ragged-red-fibers [112], mitochondrial acidosis and strokes [113], spastic paraplegia [114], and optic atrophy syndrome [115]. Therefore, NIR light is significant for applications to eye and neuron therapies to retinal damage by correction of mitochondrial disorders. For instance, the beneficial NIR light can reverse optic nerve injuries by use of helium-neon laser in models of rabbit and rat [116, 117]. In all, NIR light is effective on moderate certain injuries of eyes and nerves.

\section{Treatment of Myopia by NIR Light}

As suggested, the myopia epidemic effects the entire world [118-124] (also reviewed in [125]). Higher Myopia can result in severe retinal tears and detachment, choroidal degeneration, glaucoma and cataract, causing a large number of blindness in U.S. [126-130]. Higher order aberrations refer to optical imperfections in eyes that affect quality of retinal image, resulting in low quality of retinal image. This principle has been applied to control of myopia by orthokeratology, near addition spectacle lenses and soft contact lenses with dual-focus and multi-focus, and its potential significance to myopia control is enormous [131]. We have reported that $1 \%$ atropine retards progression of moderate myopia in Chinese school children in a mega clinical investigation [132]. Therefore, such level of prevalence for myopia is a very serious problem in public health. As people around the world are aging, myopia prevalence is continually rising [133] unless we can devise ways to block, or at least reduce, myopia development in children.

Myopia, a refractive errors disease, is increasingly common, causing blindness worldwide, likely by light triggered retina-to-sclera changes [134]. In postnatal refractive development, long-wavelength light may cause similar refractive error to that in myopia [135]. However, long wavelengths are not closely associated with promotion of myopia development in an infant monkey model [136]. Animals and human infants have eyes with large 
refractive errors [137-142]. Orthokeratology, using gas permeable contact lenses to reduce refractive errors from myopia, is currently widely used for adolescent myopia control (reviewed in [143]). Once myopia occurs, orthokeratology can retard myopia progression, by using prismatic bifocal lenses and multifocal contact lenses as soon as possible [13]. Increased outdoor activities are also effective to prevent myopia occurrence and to retard shift of refractive error from myopia, but not to decrease progression of already myopic eyes (reviewed in [144]). Through aging, the axial length is adjusted to match the eye's optics, reaching the state called emmetropia where retina is at the focal plane. The activation mechanism of emmetropization is believed that in the postnatal eye, elongation rate of eyes is set to align retina to eyes' focal plane [145-149]. Emmetropization may respond to defocus by wavelength differently because animals may adjust refractive state by monochromatic light rather than white light, are relatively more hyperopic by blue light and relatively more myopic by red light [150]. The composition of wavelength is closely associated with refractive errors and thus myopia, for example, flickering blue light promotes refractive decreases such as myopia, and upon returning to colony lighting, refractions may return to emmetropia, suggesting that flicker light may be closely linked to signaling defocus [151]. Red light may alter refractive development by decreasing elongation of vitreous chamber and increasing choroidal thickness, suggesting that long-wavelength light with narrow band may retard axial elongation induced by hyperopic defocus and form deprivation, probably due to activating signals linked to myopic defocus [131]. By constant adjustment of refractive state, emmetropization keeps approximate emmetropia in the entire postnatal period [146, 147, 152-156]. In early postnatal period, emmetropization responds roughly to the refractive error. As people are maturing, optics at eye front gradually adjusts the focal plane to retina, retarding axial elongation and compensating for plus lens to make eyes emmetropic if wearing lens and hyperopic if lens are removed [146, 148, 152, 154, 157-164]. In postnatal development, a state of near-emmetropic refractory is gradually reached. Emmetropization is still active in juvenile to adolescent stages, remaining emmetropia though a long period in axial length growth of eyes continuously. Even in the older ages, strong response to increased hyperopia by wearing a minus lens can be helpful [160, 165-167]. In contrast, capability of emmetropization to adjust to a plus lens decreases quickly as aging. However, juvenile tree shrews wearing plus lenses cannot retard the elongation rate of eyes. In fact, elongation would continue, and eyes are still myopic even with lens [168]. Without compensation of plus lenses, young, from juvenile to adolescent, tree shrews can recover quickly from induced myopia [154], suggesting that emmetropization may respond to myopic refractive state in an extended period in those animals [154, 169].

Recently, we have reviewed how myopia can be retarded by multifocal contact lenses [170]. In fact, bright light can suppress myopia progression by activating dopamine D1 receptor [171]. In addition, red light can promote progressive myopia and blue light may cause progressive hyperopia in chick model, and such inductions can be reversed to hyperopia and myopia if the red and blue lights are switched, suggesting that manipulation of chromaticity may produce beneficial effects to myopia [172].

Unfortunately, we still do not know why plus lenses do not slow down axial elongation or refractive compensation during aging of young animals. It is still unclear why normal eyes lack response to plus lenses while eyes with induced myopia can recover from axial elongation. It is probably in normal eyes, emmetropization may not retard axial elongation below threshold of a pre-programmed minimum. In the situation that eyes are elongated by minus lens wear, it is likely that sclera under remodeling of extracellular matrix has changed certain gene expression at mRNA and protein levels [173-175].

\section{Prospective for NIR Light Therapy}

NIR light therapy is an effective method for treatment of various tissues such as eyes and brains without side effects. Researchers around the world should focus on delineating the action mechanism of NIR light for the therapeutic effects of various human diseases and provide scientific evidence to support it as a new major field of medicine. This therapy has potential to be a "miracle medicine" to cure many diseases in near future. Further work is needed for development of new NIR light equipment, establishment of various standard treatment protocols by NIR light therapy, and application of this therapy to various medical fields around the world.

\section{Conclusions}

NIR light, or PBM, is a promising and powerful method to mediate biological functions via low power light wavelength from red to near-infrared regions. Eyes and neurons rely on cytochrome c oxidase to generate energy for metabolic process. NIR light can penetrate these tissues and assist recoveries of neurons in methanol intoxication, optic nerve trauma and neuropathy, retinal injuries and pigmentosa, and 
macular degeneration. NIR light can also help brains to recover from atherothrombotic stroke, brain injury, and neurodegeneration. No side effects have been observed from animals and humans. Therefore, NIR light could be a safe and effective method for a wide range of applications in ophthalmological and neurological fields in the near future.

\section{Competing Interests}

The authors have declared that no competing interest exists.

\section{References}

1. Rojas JC, Lee J, John JM, Gonzalez-Lima F. Neuroprotective effects of near-infrared light in an in vivo model of mitochondrial optic neuropathy. J Neurosci. 2008; 28: 13511-21.

2. Hochman L. Photobiomodulation Therapy in Veterinary Medicine: A Review. Top Companion Anim Med. 2018; 33: 83-8.

3. Sommer AP, Pinheiro AL, Mester AR, Franke RP, Whelan HT. Biostimulatory windows in low-intensity laser activation: lasers, scanners, and NASA's light-emitting diode array system. J Clin Laser Med Surg. 2001; 19: 29-33.

4. Karu TI. Mitochondrial signaling in mammalian cells activated by red and near-IR radiation. Photochem Photobiol. 2008; 84: 1091-9.

5. Chung H, Dai T, Sharma SK, Huang YY, Carroll JD, Hamblin MR. The nuts and bolts of low-level laser (light) therapy. Ann Biomed Eng. 2012; 40: 516-33.

6. Albarracin R, Eells J, Valter K. Photobiomodulation protects the retina from light-induced photoreceptor degeneration. Invest Ophthalmol Vis Sci. 2011; 52: 3582-92.

7. Merry GF, Munk MR, Dotson RS, Walker MG, Devenyi RG. Photobiomodulation reduces drusen volume and improves visual acuity and contrast sensitivity in dry age-related macular degeneration. Acta Ophthalmol. 2017; 95: e270-e7.

8. Fuma S, Murase H, Kuse Y, Tsuruma K, Shimazawa M, Hara H. Photobiomodulation with $670 \mathrm{~nm}$ light increased phagocytosis in human retinal pigment epithelial cells. Mol Vis. 2015; 21: 883-92.

9. Cheng Y, Du Y, Liu H, Tang J, Veenstra A, Kern TS. Photobiomodulation Inhibits Long-term Structural and Functional Lesions of Diabetic Retinopathy. Diabetes. 2018; 67: 291-8.

10. Desmet KD, Paz DA, Corry JJ, Eells JT, Wong-Riley MT, Henry MM, et al. Clinical and experimental applications of NIR-LED photobiomodulation. Photomed Laser Surg. 2006; 24: 121-8.

11. Morton CA, McKenna KE, Rhodes LE, British Association of Dermatologists Therapy G, Audit S, the British Photodermatology G. Guidelines for topical photodynamic therapy: update. Br J Dermatol. 2008; 159: 1245-66.

12. Fork RL. Laser stimulation of nerve cells in Aplysia. Science. 1971; 171: 907-8.

13. de Freitas LF, Hamblin MR. Proposed Mechanisms of Photobiomodulation or Low-Level Light Therapy. IEEE J Sel Top Quantum Electron. 2016; 22.

14. Tafur J, Mills PJ. Low-intensity light therapy: exploring the role of redox mechanisms. Photomed Laser Surg. 2008; 26: 323-8.

15. Eells JT, Wong-Riley MT, VerHoeve J, Henry M, Buchman EV, Kane MP, et al. Mitochondrial signal transduction in accelerated wound and retinal healing by near-infrared light therapy. Mitochondrion. 2004; 4: 559-67.

16. Wong-Riley MT, Liang HL, Eells JT, Chance B, Henry MM, Buchmann E, et al. Photobiomodulation directly benefits primary neurons functionally inactivated by toxins: role of cytochrome c oxidase. J Biol Chem. 2005; 280: 4761-71.

17. Zhang $\mathrm{Y}$, Song $\mathrm{S}$, Fong $\mathrm{CC}$, Tsang $\mathrm{CH}$, Yang $\mathrm{Z}$, Yang $\mathrm{M}$. cDNA microarray analysis of gene expression profiles in human fibroblast cells irradiated with red light. J Invest Dermatol. 2003; 120: 849-57.

18. Karu T. Primary and secondary mechanisms of action of visible to near-IR radiation on cells. J Photochem Photobiol B. 1999; 49: 1-17.

19. Kubota S, Yang JT. Bis[cyclo(histidylhistidine)]copper(II) complex that mimicks the active center of superoxide dismutase has its catalytic activity. Proc Natl Acad Sci U S A. 1984; 81: 3283-6.

20. Greco M, Guida G, Perlino E, Marra E, Quagliariello E. Increase in RNA and protein synthesis by mitochondria irradiated with helium-neon laser. Biochem Biophys Res Commun. 1989; 163: 1428-34.
21. Karu T. Laser biostimulation: a photobiological phenomenon. J Photochem Photobiol B. 1989; 3: 638-40.

22. Pastore D, Greco M, Passarella S. Specific helium-neon laser sensitivity of the purified cytochrome c oxidase. Int J Radiat Biol. 2000; 76: 863-70.

23. Yamanaka T, Fukumori Y, Numata M, Yamazaki T. The variety of molecular properties of bacterial cytochromes containing heme a. Ann N Y Acad Sci. 1988; 550: 39-46.

24. Wong-Riley MT. Energy metabolism of the visual system. Eye Brain. 2010; 2: 99-116.

25. Hatefi Y. The mitochondrial electron transport and oxidative phosphorylation system. Annu Rev Biochem. 1985; 54: 1015-69.

26. Sakata JT, Crews D, Gonzalez-Lima F. Behavioral correlates of differences in neural metabolic capacity. Brain Res Brain Res Rev. 2005; 48: 1-15.

27. Wong-Riley MT. Cytochrome oxidase: an endogenous metabolic marker for neuronal activity. Trends Neurosci. 1989; 12: 94-101.

28. Karu TI, Pyatibrat LV, Kalendo GS, Esenaliev RO. Effects of monochromatic low-intensity light and laser irradiation on adhesion of HeLa cells in vitro. Lasers Surg Med. 1996; 18: 171-7.

29. Karu TI, Pyatibrat LV, Kolyakov SF, Afanasyeva NI. Absorption measurements of cell monolayers relevant to mechanisms of laser phototherapy: reduction or oxidation of cytochrome c oxidase under laser radiation at $632.8 \mathrm{~nm}$. Photomed Laser Surg. 2008; 26: 593-9.

30. Calabrese EJ, Stanek EJ, 3rd, Nascarella MA, Hoffmann GR. Hormesis predicts low-dose responses better than threshold models. Int J Toxicol. 2008; 27: 369-78.

31. Mussttaf RA, Jenkins DFL, Jha AN. Assessing the impact of low level laser therapy (LLLT) on biological systems: a review. Int J Radiat Biol. 2019; 95: 120-43.

32. Yu W, Naim JO, Lanzafame RJ. The effect of laser irradiation on the release of bFGF from 3T3 fibroblasts. Photochem Photobiol. 1994; 59: 167-70.

33. Eells JT, Gopalakrishnan S, Valter K. Near-Infrared Photobiomodulation in Retinal Injury and Disease. Adv Exp Med Biol. 2016; 854: 437-41.

34. Mester E, Spiry T, Szende B, Tota JG. Effect of laser rays on wound healing. Am J Surg. 1971; 122: 532-5.

35. Viegas VN, Abreu ME, Viezzer C, Machado DC, Filho MS, Silva DN, et al. Effect of low-level laser therapy on inflammatory reactions during wound healing: comparison with meloxicam. Photomed Laser Surg. 2007; 25: 467-73.

36. Wu X, Dmitriev AE, Cardoso MJ, Viers-Costello AG, Borke RC, Streeter J, et al. $810 \mathrm{~nm}$ Wavelength light: an effective therapy for transected or contused rat spinal cord. Lasers Surg Med. 2009; 41: 36-41.

37. Neiburger EJ. Rapid healing of gingival incisions by the helium-neon diode laser. J Mass Dent Soc. 1999; 48: 8-13, 40.

38. Whelan HT, Connelly JF, Hodgson BD, Barbeau L, Post AC, Bullard G, et al. NASA light-emitting diodes for the prevention of oral mucositis in pediatric bone marrow transplant patients. J Clin Laser Med Surg. 2002; 20: 319-24.

39. Schindl A, Schindl M, Pernerstorfer-Schon H, Mossbacher U, Schindl L. Low intensity laser irradiation in the treatment of recalcitrant radiation ulcers in patients with breast cancer--long-term results of 3 cases. Photodermatol Photoimmunol Photomed. 2000; 16: 34-7.

40. Medrado AR, Pugliese LS, Reis SR, Andrade ZA. Influence of low level laser therapy on wound healing and its biological action upon myofibroblasts. Lasers Surg Med. 2003; 32: 239-44.

41. Gigo-Benato D, Geuna S, Rochkind S. Phototherapy for enhancing peripheral nerve repair: a review of the literature. Muscle Nerve. 2005; 31: 694-701.

42. Anders JJ, Geuna S, Rochkind S. Phototherapy promotes regeneration and functional recovery of injured peripheral nerve. Neurol Res. 2004; 26: $233-9$.

43. Anders JJ, Borke RC, Woolery SK, Van de Merwe WP. Low power laser irradiation alters the rate of regeneration of the rat facial nerve. Lasers Surg Med. 1993; 13: 72-82.

44. Branco K, Naeser MA. Carpal tunnel syndrome: clinical outcome after low-level laser acupuncture, microamps transcutaneous electrical nerve stimulation, and other alternative therapies--an open protocol study. J Altern Complement Med. 1999; 5: 5-26.

45. Irvine J, Chong SL, Amirjani N, Chan KM. Double-blind randomized controlled trial of low-level laser therapy in carpal tunnel syndrome. Muscle Nerve. 2004; 30: 182-7.

46. Simunovic Z, Ivankovich AD, Depolo A. Wound healing of animal and human body sport and traffic accident injuries using low-level laser therapy treatment: a randomized clinical study of seventy-four patients with control group. J Clin Laser Med Surg. 2000; 18: 67-73.

47. Ng TF, Streilein JW. Light-induced migration of retinal microglia into the subretinal space. Invest Ophthalmol Vis Sci. 2001; 42: 3301-10. 
48. Gordon WC, Casey DM, Lukiw WJ, Bazan NG. DNA damage and repair in light-induced photoreceptor degeneration. Invest Ophthalmol Vis Sci. 2002; 43: 3511-21.

49. Rutar M, Provis JM, Valter K. Brief exposure to damaging light causes focal recruitment of macrophages, and long-term destabilization of photoreceptors in the albino rat retina. Curr Eye Res. 2010; 35: 631-43.

50. Ni YQ, Xu GZ, Hu WZ, Shi L, Qin YW, Da CD. Neuroprotective effects of naloxone against light-induced photoreceptor degeneration through inhibiting retinal microglial activation. Invest Ophthalmol Vis Sci. 2008; 49: 2589-98.

51. Yang L, Kim JH, Kovacs KD, Arroyo JG, Chen DF. Minocycline inhibition of photoreceptor degeneration. Arch Ophthalmol. 2009; 127: 1475-80.

52. Liang HL, Whelan HT, Eells JT, Meng H, Buchmann E, Lerch-Gaggl A, et al. Photobiomodulation partially rescues visual cortical neurons from cyanide-induced apoptosis. Neuroscience. 2006; 139: 639-49.

53. Eells JT, Henry MM, Summerfelt P, Wong-Riley MT, Buchmann EV, Kane M, et al. Therapeutic photobiomodulation for methanol-induced retinal toxicity. Proc Natl Acad Sci U S A. 2003; 100: 3439-44.

54. Heinig N, Schumann U, Calzia D, Panfoli I, Ader M, Schmidt MHH, et al. Photobiomodulation Mediates Neuroprotection against Blue Light Induced Retinal Photoreceptor Degeneration. Int J Mol Sci. 2020; 21.

55. Ying R, Liang HL, Whelan HT, Eells JT, Wong-Riley MT. Pretreatment with near-infrared light via light-emitting diode provides added benefit against rotenone- and MPP+-induced neurotoxicity. Brain Res. 2008; 1243: $167-73$

56. Kokkinopoulos I, Colman A, Hogg C, Heckenlively J, Jeffery G. Age-related retinal inflammation is reduced by $670 \mathrm{~nm}$ light via increased mitochondrial membrane potential. Neurobiol Aging. 2013;34: 602-9.

57. Del Olmo-Aguado S, Nunez-Alvarez C, Osborne NN. Red light of the visual spectrum attenuates cell death in culture and retinal ganglion cell death in situ. Acta Ophthalmol. 2016; 94: e481-91.

58. Sivapathasuntharam C, Sivaprasad S, Hogg C, Jeffery G. Aging retinal function is improved by near infrared light $(670 \mathrm{~nm})$ that is associated with corrected mitochondrial decline. Neurobiol Aging. 2017; 52: 66-70.

59. Kokkinopoulos I. $670 \mathrm{~nm}$ LED ameliorates inflammation in the $\mathrm{CFH}(-/-)$ mouse neural retina. J Photochem Photobiol B. 2013; 122: 24-31.

60. Begum R, Powner MB, Hudson N, Hogg C, Jeffery G. Treatment with $670 \mathrm{~nm}$ light up regulates cytochrome $C$ oxidase expression and reduces inflammation in an age-related macular degeneration model. PLoS One. 2013; 8: e57828.

61. Kaynezhad P, Tachtsidis I, Jeffery G. Optical monitoring of retinal respiration in real time: $670 \mathrm{~nm}$ light increases the redox state of mitochondria. Exp Eye Res. 2016; 152: 88-93.

62. Albarracin R, Natoli R, Rutar M, Valter K, Provis J. $670 \mathrm{~nm}$ light mitigates oxygen-induced degeneration in C57BL/ $6 \mathrm{~J}$ mouse retina. BMC Neurosci. 2013; 14: 125

63. Rutar M, Natoli R, Albarracin R, Valter K, Provis J. 670-nm light treatment reduces complement propagation following retinal degeneration. J Neuroinflammation. 2012; 9: 257.

64. Natoli R, Valter K, Barbosa M, Dahlstrom J, Rutar M, Kent A, et al. $670 \mathrm{~nm}$ photobiomodulation as a novel protection against retinopathy of prematurity: evidence from oxygen induced retinopathy models. PLoS One. 2013; 8: e72135.

65. Natoli R, Zhu Y, Valter K, Bisti S, Eells J, Stone J. Gene and noncoding RNA regulation underlying photoreceptor protection: microarray study of dietary antioxidant saffron and photobiomodulation in rat retina. Mol Vis. 2010; 16: 1801-22

66. Karu TI, Afanas'eva NI. [Cytochrome c oxidase as the primary photoacceptor upon laser exposure of cultured cells to visible and near IR-range light]. Dokl Akad Nauk. 1995; 342: 693-5.

67. Silveira PC, Streck EL, Pinho RA. Evaluation of mitochondrial respiratory chain activity in wound healing by low-level laser therapy. J Photochem Photobiol B. 2007; 86: 279-82.

68. Gkotsi D, Begum R, Salt T, Lascaratos G, Hogg C, Chau KY, et al. Recharging mitochondrial batteries in old eyes. Near infra-red increases ATP. Exp Eye Res. 2014; 122: 50-3.

69. Iglesias-Rey R, Castillo J. New strategies for ischemic stroke: internal photobiomodulation therapy. Neural Regen Res. 2020; 15: 1658-9.

70. Casalechi HL, Dumont AJL, Ferreira LAB, de Paiva PRV, Machado C, de Carvalho PTC, et al. Acute effects of photobiomodulation therapy and magnetic field on functional mobility in stroke survivors: a randomized, sham-controlled, triple-blind, crossover, clinical trial. Lasers Med Sci. 2019

71. Finsterer J, Zarrouk-Mahjoub S. Treatment of muscle weakness in neuromuscular disorders. Expert Rev Neurother. 2016; 16: 1383-95.

72. Leavitt M, Charles G, Heyman E, Michaels D. HairMax LaserComb laser phototherapy device in the treatment of male androgenetic alopecia: A randomized, double-blind, sham device-controlled, multicentre trial. Clin Drug Investig. 2009; 29: 283-92.

73. Zamani ARN, Saberianpour S, Geranmayeh MH, Bani F, Haghighi L, Rahbarghazi R. Modulatory effect of photobiomodulation on stem cell epigenetic memory: a highlight on differentiation capacity. Lasers Med Sci. 2020; 35: 299-306.

74. Maruani J, Geoffroy PA. Bright Light as a Personalized Precision Treatment of Mood Disorders. Front Psychiatry. 2019; 10: 85.

75. Huang YY, Chen AC, Carroll JD, Hamblin MR. Biphasic dose response in low level light therapy. Dose Response. 2009; 7: 358-83.

76. Huang YY, Sharma SK, Carroll J, Hamblin MR. Biphasic dose response in low level light therapy - an update. Dose Response. 2011; 9: 602-18.

77. Karu T. Mitochondrial mechanisms of photobiomodulation in context of new data about multiple roles of ATP. Photomed Laser Surg. 2010; 28: 159-60.

78. Clarke G, Lumsden CJ, McInnes RR. Inherited neurodegenerative diseases: the one-hit model of neurodegeneration. Hum Mol Genet. 2001; 10: 2269-75.

79. Lampl Y, Zivin JA, Fisher M, Lew R, Welin L, Dahlof B, et al. Infrared laser therapy for ischemic stroke: a new treatment strategy: results of the NeuroThera Effectiveness and Safety Trial-1 (NEST-1). Stroke. 2007; 38: 1843-9.

80. Garbuzova-Davis S, Willing AE, Saporta S, Bickford PC, Gemma C, Chen $\mathrm{N}$, et al. Novel cell therapy approaches for brain repair. Prog Brain Res. 2006; 157: 207-22

81. Ilic S, Leichliter S, Streeter J, Oron A, DeTaboada L, Oron U. Effects of power densities, continuous and pulse frequencies, and number of sessions of low-level laser therapy on intact rat brain. Photomed Laser Surg. 2006; 24: 458-66.

82. Oron U, Yaakobi T, Oron A, Mordechovitz D, Shofti R, Hayam G, et al. Low-energy laser irradiation reduces formation of scar tissue after myocardial infarction in rats and dogs. Circulation. 2001; 103: 296-301.

83. Oron U, Yaakobi T, Oron A, Hayam G, Gepstein L, Rubin O, et al. Attenuation of infarct size in rats and dogs after myocardial infarction by low-energy laser irradiation. Lasers Surg Med. 2001; 28: 204-11.

84. Whelan HT, Buchmann EV, Dhokalia A, Kane MP, Whelan NT, Wong-Riley MT, et al. Effect of NASA light-emitting diode irradiation on molecular changes for wound healing in diabetic mice. J Clin Laser Med Surg. 2003; 21: 67-74.

85. Karu TI, Pyatibrat LV, Kalendo GS. Photobiological modulation of cell attachment via cytochrome c oxidase. Photochem Photobiol Sci. 2004; 3: 211-6.

86. Hamblin MR. Mechanisms and Mitochondrial Redox Signaling in Photobiomodulation. Photochem Photobiol. 2018; 94: 199-212.

87. Beirne K, Rozanowska M, Votruba M. Photostimulation of mitochondria as a treatment for retinal neurodegeneration. Mitochondrion. 2017; 36: 85-95.

88. Peat FJ, Colbath AC, Bentsen LM, Goodrich LR, King MR. In Vitro Effects of High-Intensity Laser Photobiomodulation on Equine Bone Marrow-Derived Mesenchymal Stem Cell Viability and Cytokine Expression. Photomed Laser Surg. 2018; 36: 83-91.

89. Sengupta A, Chaffiol A, Mace E, Caplette R, Desrosiers M, Lampic M, et al. Red-shifted channelrhodopsin stimulation restores light responses in blind mice, macaque retina, and human retina. EMBO Mol Med. 2016; 8: 1248-64.

90. Qu C, Cao W, Fan Y, Lin Y. Near-infrared light protect the photoreceptor from light-induced damage in rats. Adv Exp Med Biol. 2010; 664: 365-74.

91. Geneva, II. Photobiomodulation for the treatment of retinal diseases: a review. Int J Ophthalmol. 2016; 9: 145-52.

92. Shen J, Yang X, Dong A, Petters RM, Peng YW, Wong F, et al. Oxidative damage is a potential cause of cone cell death in retinitis pigmentosa. J Cell Physiol. 2005; 203: 457-64.

93. Stone J, Maslim J, Valter-Kocsi K, Mervin K, Bowers F, Chu Y, et al. Mechanisms of photoreceptor death and survival in mammalian retina. Prog Retin Eye Res. 1999; 18: 689-735.

94. Jarrett SG, Boulton ME. Consequences of oxidative stress in age-related macular degeneration. Mol Aspects Med. 2012; 33: 399-417.

95. Jester JV, Moller-Pedersen T, Huang J, Sax CM, Kays WT, Cavangh HD, et al. The cellular basis of corneal transparency: evidence for 'corneal crystallins'. J Cell Sci. 1999; 112 ( Pt 5): 613-22.

96. Ames A, 3rd, Li YY, Heher EC, Kimble CR. Energy metabolism of rabbit retina as related to function: high cost of $\mathrm{Na}+$ transport. J Neurosci. 1992; 12: 840-53.

97. Astrup J, Sorensen PM, Sorensen HR. Oxygen and glucose consumption related to $\mathrm{Na}+-\mathrm{K}+$ transport in canine brain. Stroke. 1981; 12: 726-30.

98. Kann O, Kovacs R. Mitochondria and neuronal activity. AmJPhysiol Cell Physiol. 2007; 292: C641-C57.

99. Beretta S, Wood JP, Derham B, Sala G, Tremolizzo L, Ferrarese C, et al. Partial mitochondrial complex I inhibition induces oxidative damage 
and perturbs glutamate transport in primary retinal cultures. Relevance to Leber Hereditary Optic Neuropathy (LHON). Neurobiol Dis. 2006; 24: 308-17.

100. Levin LA, Peeples P. History of neuroprotection and rationale as a therapy for glaucoma. Am J Manag Care. 2008; 14: S11-4.

101. Rojas JC, Gonzalez-Lima F. Mitochondrial optic neuropathy: In vivo model of neurodegeneration and neuroprotective strategies. Eye Brain. 2010; 2: 21-37.

102. Abu-Amero KK, Bosley TM. Mitochondrial abnormalities in patients with LHON-like optic neuropathies. Invest Ophthalmol Vis Sci. 2006; 47: 4211-20.

103. Mirra S, Marfany G. Mitochondrial Gymnastics in Retinal Cells: A Resilience Mechanism Against Oxidative Stress and Neurodegeneration. Adv Exp Med Biol. 2019; 1185: 513-7.

104. Iseri PK, Altinas O, Tokay T, Yuksel N. Relationship between cognitive impairment and retinal morphological and visual functional abnormalities in Alzheimer disease. J Neuroophthalmol. 2006; 26: 18-24.

105. Fortuna F, Barboni P, Liguori R, Valentino ML, Savini G, Gellera C, et al. Visual system involvement in patients with Friedreich's ataxia. Brain. 2009; 132: 116-23.

106. Danesh-Meyer HV, Birch H, Ku JY, Carroll S, Gamble G. Reduction of optic nerve fibers in patients with Alzheimer disease identified by laser imaging. Neurology. 2006; 67: 1852-4.

107. Sadun AA, Bassi CJ. Optic nerve damage in Alzheimer's disease. Ophthalmology. 1990; 97: 9-17.

108. Sheremet NL, Khanakova NA, Nevinitsyna TA, Tsygankova PG, Itkis Iu S, Krylova TD, et al. [Modern opportunities and prospects for studying pathogenesis, diagnosing and treating hereditary optic neuropathies]. Vestn Oftalmol. 2014; 130: 62-70.

109. Borit A. Leigh's necrotizing encephalomyelopathy. Neuro-ophthalmological abnormalities. Arch Ophthalmol. 1971; 85: 438-42.

110. DiMauro S. Mitochondrial encephalomyopathies: back to Mendelian genetics. Ann Neurol. 1999; 45: 693-4.

111. Carelli V, Ross-Cisneros FN, Sadun AA. Optic nerve degeneration and mitochondrial dysfunction: genetic and acquired optic neuropathies. Neurochem Int. 2002; 40: 573-84.

112. Chinnery PF, Howell N, Lightowlers RN, Turnbull DM. Molecular pathology of MELAS and MERRF. The relationship between mutation load and clinical phenotypes. Brain. 1997; 120 ( Pt 10): 1713-21.

113. Hwang JM, Park HW, Kim SJ. Optic neuropathy associated with mitochondrial tRNA[Leu(UUR)] A3243G mutation. Ophthalmic Genet. 1997; 18: 101-5.

114. Casari G, De Fusco M, Ciarmatori S, Zeviani M, Mora M, Fernandez P, et al. Spastic paraplegia and OXPHOS impairment caused by mutations in paraplegin, a nuclear-encoded mitochondrial metalloprotease. Cell. 1998; 93: 973-83.

115. Tranebjaerg L, Hamel BC, Gabreels FJ, Renier WO, Van Ghelue M. A de novo missense mutation in a critical domain of the X-linked DDP gene causes the typical deafness-dystonia-optic atrophy syndrome. Eur J Hum Genet. 2000; 8: 464-7.

116. Schwartz M, Doron A, Erlich M, Lavie V, Benbasat S, Belkin M, et al. Effects of low-energy $\mathrm{He}-\mathrm{Ne}$ laser irradiation on posttraumatic degeneration of adult rabbit optic nerve. Lasers Surg Med. 1987; 7: 51-5.

117. Assia E, Rosner M, Belkin M, Solomon A, Schwartz M. Temporal parameters of low energy laser irradiation for optimal delay of post-traumatic degeneration of rat optic nerve. Brain Res. 1989; 476: 205-12.

118. Grzybowski A, Kanclerz P, Tsubota K, Lanca C, Saw SM. A review on the epidemiology of myopia in school children worldwide. BMC Ophthalmol. 2020; 20: 27.

119. Sperduto RD, Seigel D, Roberts J, Rowland M. Prevalence of myopia in the United States. Arch Ophthalmol. 1983; 101: 405-7.

120. Lin LL, Chen CJ, Hung PT, Ko LS. Nation-wide survey of myopia among schoolchildren in Taiwan, 1986. Acta Ophthalmol Suppl. 1988; 185: 29-33.

121. Quek TP, Chua CG, Chong CS, Chong JH, Hey HW, Lee J, et al. Prevalence of refractive errors in teenage high school students in Singapore. Ophthalmic Physiol Opt. 2004; 24: 47-55.

122. Vitale S, Sperduto RD, Ferris FL, 3rd. Increased prevalence of myopia in the United States between 1971-1972 and 1999-2004. Arch Ophthalmol. 2009; 127: 1632-9.

123. Sun J, Zhou J, Zhao P, Lian J, Zhu H, Zhou Y, et al. High prevalence of myopia and high myopia in 5060 Chinese university students in Shanghai. Invest Ophthalmol Vis Sci. 2012; 53: 7504-9.

124. Dolgin E. The myopia boom. Nature. 2015; 519: 276-8

125. Tran HDM, Tran YH, Tran TD, Jong M, Coroneo M, Sankaridurg P. A Review of Myopia Control with Atropine. J Ocul Pharmacol Ther. 2018; 34: 374-9.
126. Burton TC. The influence of refractive error and lattice degeneration on the incidence of retinal detachment. Trans Am Ophthalmol Soc. 1989; 87: 143-55; discussion 55-7.

127. Zadnik K. It's the retina, stupid. Optom Vis Sci. 2001; 78: 179-80.

128. Vongphanit J, Mitchell P, Wang JJ. Prevalence and progression of myopic retinopathy in an older population. Ophthalmology. 2002; 109: 704-11.

129. Saw SM, Gazzard G, Shih-Yen EC, Chua WH. Myopia and associated pathological complications. Ophthalmic Physiol Opt. 2005; 25: 381-91.

130. Jones LA, Sinnott LT, Mutti DO, Mitchell GL, Moeschberger ML, Zadnik K. Parental history of myopia, sports and outdoor activities, and future myopia. Invest Ophthalmol Vis Sci. 2007; 48: 3524-32.

131. Hung LF, Arumugam B, She Z, Ostrin L, Smith EL, 3rd. Narrow-band, long-wavelength lighting promotes hyperopia and retards vision-induced myopia in infant rhesus monkeys. Exp Eye Res. 2018; 176: $147-60$

132. Zhu Q, Tang Y, Guo L, Tighe S, Zhou Y, Zhang X, et al. Efficacy and Safety of 1\% Atropine on Retardation of Moderate Myopia Progression in Chinese School Children. Int J Med Sci. 2020; 17: 176-81.

133. Holden BA, Jong M, Davis S, Wilson D, Fricke T, Resnikoff S. Nearly 1 billion myopes at risk of myopia-related sight-threatening conditions by 2050 - time to act now. Clin Exp Optom. 2015; 98: 491-3.

134. Tedja MS, Wojciechowski R, Hysi PG, Eriksson N, Furlotte NA, Verhoeven VJM, et al. Genome-wide association meta-analysis highlights light-induced signaling as a driver for refractive error. Nat Genet. 2018; 50: 834-48.

135. Ward AH, Norton TT, Huisingh CE, Gawne TJ. The hyperopic effect of narrow-band long-wavelength light in tree shrews increases non-linearly with duration. Vision Res. 2018; 146-147: 9-17.

136. Smith EL, 3rd, Hung LF, Arumugam B, Holden BA, Neitz M, Neitz J. Effects of Long-Wavelength Lighting on Refractive Development in Infant Rhesus Monkeys. Invest Ophthalmol Vis Sci. 2015; 56: 6490-500.

137. Norton TT, McBrien NA. Normal development of refractive state and ocular component dimensions in the tree shrew (Tupaia belangeri). Vision Res. 1992; 32: 833-42.

138. Cook RC, Glasscock RE. Refractive and ocular findings in the newborn. Am J Ophthalmol. 1951; 34: 1407-13.

139. Graham B, Judge SJ. Normal development of refractive state and ocular component dimensions in the marmoset (Callithrix jacchus). Vision Res. 1999; 39: 177-87.

140. Bradley DV, Fernandes A, Lynn M, Tigges M, Boothe RG. Emmetropization in the rhesus monkey (Macaca mulatta): birth to young adulthood. Invest Ophthalmol Vis Sci. 1999; 40: 214-29.

141. Pickett-Seltner RL, Sivak JG, Pasternak JJ. Experimentally induced myopia in chicks: morphometric and biochemical analysis during the first 14 days after hatching. Vision Res. 1988; 28: 323-8.

142. Chen J, Xie A, Hou L, Su Y, Lu F, Thorn F. Cycloplegic and noncycloplegic refractions of Chinese neonatal infants. Invest Ophthalmol Vis Sci. 2011; 52: 2456-61.

143. Lipson MJ, Brooks MM, Koffler BH. The Role of Orthokeratology in Myopia Control: A Review. Eye Contact Lens. 2018; 44: 224-30.

144. Xiong S, Sankaridurg P, Naduvilath T, Zang J, Zou H, Zhu J, et al. Time spent in outdoor activities in relation to myopia prevention and control: a meta-analysis and systematic review. Acta Ophthalmol. 2017; 95: 551-66.

145. Schaeffel F, Howland HC. Properties of the feedback loops controlling eye growth and refractive state in the chicken. Vision Res. 1991; 31: 717-34

146. Wildsoet CF. Active emmetropization--evidence for its existence and ramifications for clinical practice. Ophthalmic Physiol Opt. 1997; 17: 279-90.

147. Norton TT. Animal Models of Myopia: Learning How Vision Controls the Size of the Eye. ILAR J. 1999; 40: 59-77.

148. Mutti DO, Mitchell GL, Jones LA, Friedman NE, Frane SL, Lin WK, et al. Axial growth and changes in lenticular and corneal power during emmetropization in infants. Invest Ophthalmol Vis Sci. 2005; 46: 3074-80.

149. Smith EL, 3rd, Hung LF, Huang J, Blasdel TL, Humbird TL, Bockhorst $\mathrm{KH}$. Effects of optical defocus on refractive development in monkeys: evidence for local, regionally selective mechanisms. Invest Ophthalmol Vis Sci. 2010; 51: 3864-73.

150. Rucker F. Monochromatic and white light and the regulation of eye growth. Exp Eye Res. 2019; 184: 172-82.

151. Gawne TJ, Siegwart JT, Jr., Ward AH, Norton TT. The wavelength composition and temporal modulation of ambient lighting strongly affect refractive development in young tree shrews. Exp Eye Res. 2017; 155: 75-84.

152. Wallman J, Winawer J. Homeostasis of eye growth and the question of myopia. Neuron. 2004; 43: 447-68. 
153. Amedo AO, Norton TT. Visual guidance of recovery from lens-induced myopia in tree shrews (Tupaia glis belangeri). Ophthalmic Physiol Opt. 2012; 32: 89-99.

154. Norton TT, Amedo AO, Siegwart JT, Jr. The effect of age on compensation for a negative lens and recovery from lens-induced myopia in tree shrews (Tupaia glis belangeri). Vision Res. 2010; 50: 564-76.

155. Smith EL, 3rd, Hung LF, Arumugam B. Visual regulation of refractive development: insights from animal studies. Eye (Lond). 2014; 28: 180-8.

156. Schaeffel F, Feldkaemper M. Animal models in myopia research. Clin Exp Optom. 2015; 98: 507-17.

157. Schaeffel F, Glasser A, Howland HC. Accommodation, refractive error and eye growth in chickens. Vision Res. 1988; 28: 639-57.

158. Irving EL, Sivak JG, Callender MG. Refractive plasticity of the developing chick eye. Ophthalmic Physiol Opt. 1992; 12: 448-56.

159. Hung LF, Crawford ML, Smith EL. Spectacle lenses alter eye growth and the refractive status of young monkeys. Nat Med. 1995; 1: 761-5.

160. Smith EL, 3rd, Bradley DV, Fernandes A, Boothe RG. Form deprivation myopia in adolescent monkeys. Optom Vis Sci. 1999; 76: 428-32.

161. Shen W, Sivak JG. Eyes of a lower vertebrate are susceptible to the visual environment. Invest Ophthalmol Vis Sci. 2007; 48: 4829-37.

162. Metlapally S, McBrien NA. The effect of positive lens defocus on ocular growth and emmetropization in the tree shrew. J Vis. 2008; 8: 1 -12.

163. Howlett MH, McFadden SA. Spectacle lens compensation in the pigmented guinea pig. Vision Res. 2009; 49: 219-27.

164. Troilo D, Totonelly K, Harb E. Imposed anisometropia, accommodation, and regulation of refractive state. Optom Vis Sci. 2009; 86: E31-9.

165. Norton TT, Rada JA. Reduced extracellular matrix in mammalian sclera with induced myopia. Vision Res. 1995; 35: 1271-81.

166. Papastergiou GI, Schmid GF, Laties AM, Pendrak K, Lin T, Stone RA. Induction of axial eye elongation and myopic refractive shift in one-year-old chickens. Vision Res. 1998; 38: 1883-8.

167. Troilo D, Nickla DL, Wildsoet CF. Form deprivation myopia in mature common marmosets (Callithrix jacchus). Invest Ophthalmol Vis Sci. 2000; 41: 2043-9.

168. Siegwart JT, Jr., Norton TT. Binocular lens treatment in tree shrews: Effect of age and comparison of plus lens wear with recovery from minus lens-induced myopia. Exp Eye Res. 2010; 91: 660-9.

169. Wallman J, Adams JI. Developmental aspects of experimental myopia in chicks: susceptibility, recovery and relation to emmetropization. Vision Res. 1987; 27: 1139-63.

170. Zhu Q, Liu Y, Tighe S, Zhu Y, Su X, Lu F, et al. Retardation of Myopia Progression by Multifocal Soft Contact Lenses. Int J Med Sci. 2019; 16: 198-202.

171. Chen S, Zhi Z, Ruan Q, Liu Q, Li F, Wan F, et al. Bright Light Suppresses Form-Deprivation Myopia Development With Activation of Dopamine D1 Receptor Signaling in the ON Pathway in Retina. Invest Ophthalmol Vis Sci. 2017; 58: 2306-16.

172. Foulds WS, Barathi VA, Luu CD. Progressive myopia or hyperopia can be induced in chicks and reversed by manipulation of the chromaticity of ambient light. Invest Ophthalmol Vis Sci. 2013; 54: 8004-12.

173. Siegwart JT, Jr., Norton TT. Regulation of the mechanical properties of tree shrew sclera by the visual environment. Vision Res. 1999; 39: 387-407.

174. Guo L, Frost MR, He L, Siegwart JT, Jr., Norton TT. Gene expression signatures in tree shrew sclera in response to three myopiagenic conditions. Invest Ophthalmol Vis Sci. 2013; 54: 6806-19.

175. Grytz R, Siegwart JT, Jr. Changing material properties of the tree shrew sclera during minus lens compensation and recovery. Invest Ophthalmol Vis Sci. 2015; 56: 2065-78. 